\title{
Performance verification of pre-PCR and real-time PCR step in the molecular diagnosis of pneumococcal meningitis cases.
}

\author{
Soumaya Chaiboub ${ }^{1,2^{*}}$, Réda Charof ${ }^{1}$, Aicha Qasmaoui $^{1}$, Jamila Hamamouchi $^{1}$ and El Hassan \\ Berny2 \\ ${ }^{1}$ Department of Epidemic Diseases, National Institute of Hygiene, Rabat, Morocco \\ ${ }^{2}$. Department of Biology and Health, Faculty of Science, Ibn Tofael University, Kenitra, Morocco.
}

\begin{abstract}
Isolation and determination of s.pneumoniae by culture and serological methods can be time consuming or indeterminate. Molecular diagnosis by real-time PCR is independent of the growth of the pathogen causing meningitis, and is not diminished with non-viable organisms. The aim of this study was to evaluate the performance criteria of pre-PCR-TR DNA extraction step and PCR-TR step by targeting two genes encoding s.pneumoniae. In this study we evaluated the inter-sample contamination of the pre-PCRTR step, the intermediate fidelity and the repeatability of the DNA essay. PCR-TR verification was performed by two genes targeting s. pneumoniae the Lyt A and SP 2038 gene; sensitivity, specificity and LLD were determined. Contamination rate had a value of less than $0 \%$, which is in agreement with an absence of inter-sample contamination; the repeatability and intermediate fidelity have a $\mathrm{cv}<7 \%$. The evaluation of the sensitivity and specificity of the RT-PCR assays targeted 100\% the Lyt A gene and the SP 2038 gene. The standard curve generated detected less than 10copies for the Lyt A gene and less than 100copies for the SP 2038 gene. This study showed that the pre-PCR and PCRTR assays met the performance criteria targeted in this study.
\end{abstract}

\section{INTRODUCTION:}

Pneumococcal infections are a major public health problem. the World Health Organization (WHO) estimated that 1.6 million deaths each year are attributable to pneumococcal infections, this estimate includes the deaths of 0.7 to 1 million children under the age of 5 years [1]. In africa bacterial meningitis affecting about one million people per year, with a case fatality that remains high, in the order of $10 \%$, in spite of all the strategies put in place to control this condition [2]. Conventional culturebased laboratory diagnostic methods for the identification of bacterial meningitis pathogens are more time-consuming, and in some situations, culture is not a perfect reference method for detecting the pathogen responsible

\footnotetext{
*Corresponding author: soumayachaiboub@gmail.com
}

for meningitis because of the low culture rate and its limited sensitivity (high false-negative rate), especially when patients received antibiotics prior to the lumbar puncture [3]. PCR-TR has become a powerful tool for molecular diagnosis. PCR-TR detection is independent of the growth of the diseasecausing microorganism, and is not diminished with nonviable organisms [4].

The principle of PCR is based on the amplification of a target genomic region allows to multiply a DNA molecule initially present in too small quantities to be detected [5]. The extraction and essay of DNA are integrated in the pre-analytical step of the process of analysis of DNA by PCR-TR and are considered critical, given their high importance for the realization and reliability of subsequent analytical steps of PCR-TR. In this study, we discuss the 
performance criteria of the pre-PCR-TR step and the PCR-TR step on targeting two genes encoding s.pneumoniae.

\section{Materiel and methods}

\section{Verification of extraction method:}

We evaluated the inter-sample contamination of the pre-RT-PCR DNA extraction step by extracting a strong positive known sample containing the suspension of the s.pneumoniae ATCC 49619 strain and a negative sample containing only the extraction dilution solution.Both samples were extracted at the same time the DNA extraction procedure was performed. This step ensures that negative realtime PCR results are not due to DNA extraction failure during sample pipetting and that positive PCR results are not due to cross-contamination introduced during the DNA extraction process.

DNA extraction was performed by QIAGEN QIAamp DNA Blood mini kit reagents (QIAGEN, Valencia, CA) according to the protocol recommended by the supplier. The quality and DNA essay of the obtained extracts were evaluated using the Nanodrop spectrophotometer (NanoDropOne, Thermo Fisher scientific, VerinaRd, USA) and stored at $-20^{\circ} \mathrm{C}$.

In this study we determined the repeatability. We used four CSF samples extracted on the same day by the same operator and each concentration level was repeated nine times.

intermediate fidelity is also determined at the same condition except that the time factor was changed that spaced the extraction by 15 days.

\section{PCR-TR step verification:}

This study followed the recommendations decreed by the Cofrac in the SH GTA 04 (Revision 1) for molecular biology of qualitative methods [8]. The PCR-TR verification was performed by two genes targeting s. pneumoniae the Lyt A gene and SP 2038.

The primers and TaqMan probe of The standard Genesig kit for s.pneumoniae from Genesig (genesig,Atlanta) were designed to amplify the SP2038 gene (alpha-fucosidase gene). The forward and reverse primer sequences were not provided by the
company.The SP2038 gene (alpha-fucosidase gene) is a taxonomic gene and is highly conserved from s.pneumoniae.[16]

The pneumococcal autolysin gene (LytA) oligonucleotide primers and TaqMan probe used in this study were designed by the CDC (Center for Disease Control)[9]. Details of the primers and probes for this assay are shown in Table 1.

Table1. Primers and probe used for detection of s.pneumoniae [9].

\begin{tabular}{|l|l|l|}
\hline $\begin{array}{l}\text { Tar } \\
\text { get }\end{array}$ & $\begin{array}{l}\text { Primer } \\
\text { or } \\
\text { Probe } \\
\text { Name }\end{array}$ & $\begin{array}{l}\text { Real-time Primers and Probes } \\
\text { Nucleotide Sequence (5' to 3') }\end{array}$ \\
\hline $\begin{array}{l}\text { Lyt } \\
\text { A }\end{array}$ & F373 & $\begin{array}{l}\text { ACGCAATCTAGCAGATGA } \\
\text { AGCA }\end{array}$ \\
\cline { 2 - 3 } & R424 & $\begin{array}{l}\text { TCGTGCGTTTTAATTCCAG } \\
\text { CT }\end{array}$ \\
\cline { 2 - 3 } & Pb400i & $\begin{array}{l}\text { TGCCGAAAACGC'T'TGAT } \\
\text { ACAGGGAG }\end{array}$ \\
\hline
\end{tabular}

essays of PCR-TR were performed using a CFX 96 real-time PCR system (Bio-Rad CFX96 Manager) using the following cycling parameters: A positive result was defined as a cycle threshold $(\mathrm{Ct})$ value of less than 39, fluorogenic data was collected during this step through the FAM channel.

35 culture-positive pneumococcal CSFs were used to determine PCR sensitivity. Positive samples were determined by the reference method [10]. The limit of detection (LLD) was determined using DNA extracted from Streptococcus pneumoniae strain ATCC 49619, DNA concentrations were adjusted to $97.6 \mathrm{ng} / \mu \mathrm{l}$ from which eight-fold serial dilutions (10-1 to 10-8) were made in PCR grade water. DNA preparations were then evaluated using the Nanodrop spectrophotometer (NanoDropOne,Thermo Fisher scientific,VerinaRd,USA).

Specificity was determined with 15 negative control organisms representing oral and respiratory flora, selected from laboratory bacterial stocks: Acinetobacter baumannii, H.influenzae, N. meningitidis, Enterobacter cloaceae, Citrobacter Freundii, Pseudomonas aeruginosa, Shigella boydii, Escherichia coli, Klebsiella pneumoniae, Salmonella typhimurium, and Listeria monocytogenes, Enterococcus faecalis, Streptococcus agalactiae (group B streptococci), 
Staphylococcus aureus. Streptococcus pneumoniae strain ATCC 49619 was adopted as the reference strain for reagent control culture media.

\section{Statistical analysis}

Data analysis was performed using Microsoft Excel and MedCalc statistical software. Confidence Intervals (CI) were set at 95\%.

\section{Result and discussion}

\section{Inter-sample Contamination Study:}

DNA extraction by the mini KIT is a multistep process: Cell wall lysis, DNA isolation, washing, purification and elution of DNA in elution buffer. DNA extracts must meet the requirements otherwise the tests may give false negatives and false positives due to contamination or presence of PCR inhibitors [11].

The study of inter-sample contamination was performed by a strong positive high value sample of Streptococcus pneumoniae strain ATCC 49619 and analyzed 3 times followed by a negative sample containing the dilution solution also analyzed 3 times. The calculated contamination rate gives us a value of $-0.03 \%$, which is in agreement with the absence of intersample contamination during extraction and routine assays.

\section{Repeatability study}

Four samples of fixed concentrations ( $\mathrm{c} 1=53.5$ $\mathrm{ng} / \mathrm{uL}$ and $\mathrm{c} 2=99.3 \mathrm{ng} / \mathrm{uL} / \mathrm{c} 3=7.9 \mathrm{ng} / \mathrm{ul}$ and $\mathrm{c} 4=8.4 \mathrm{ng} / \mathrm{ul}$ ) were performed on the same day by the same operator. The measurement was repeated eight times; the mean, standard deviation and covariance were determined.

Table 2. Results of the repeatability evaluation for the DNA determination by spectrophotometric method.

\begin{tabular}{|l|l|l|l|}
\hline & $\begin{array}{c}\text { Mean } \\
(\text { ng/_L) })\end{array}$ & $\begin{array}{l}\text { standard } \\
\text { deviation }\end{array}$ & CV\% \\
\hline
\end{tabular}

\footnotetext{
*Corresponding author: soumayachaiboub@gmail.com
}

\begin{tabular}{|l|l|l|l|}
$\begin{array}{c}\text { sampl } \\
\text { es }\end{array}$ & & & \\
\hline 1 & 8,38 & 0,35 & $4,17 \%$ \\
\hline 2 & 53,04 & 2,78 & $5,24 \%$ \\
\hline 3 & 99,82 & 1,93 & $6,78 \%$ \\
\hline 4 & 8,3 & 0,4 & $4,81 \%$ \\
\hline
\end{tabular}

\section{Study of the intermediate fidelity}

The intermediate fidelity is also determined under the same condition except that we changed the time factor that spaced the extraction by 15 days. Eight times measurement of 4 samples was performed to calculate the standard deviation and covariance. The covariance calculated in this study was $\mathrm{CV}<7 \%$.

\section{Real-time $P C R$ step verification:}

Evaluation of the sensitivity of RT-PCR tests by reference method confirmed samples were $100 \%$ positive $(95 \%$ confidence limits, $89.11 \%$ $100.00 \%), 100 \%(92.13 \%-100.00 \%)$

respectively for the two diagnostic genes Lyt A and SP 2038.The generated standard curve showed high sensitivities with their respective primer and probe pairs, with an equivalent detection limit of $<10$ copies, with $\mathrm{R} 2>0.99$ for the Lyt A gene and $<100$ copies for the SP 2038 gene primers.

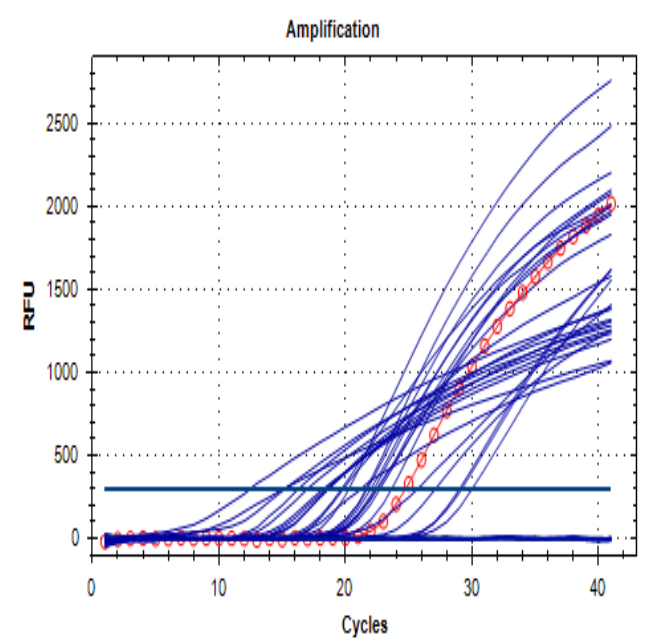

Fig. 1. Amplification curves generated by CFX 96 of the CSFs used for the sensitivity study (The red curve shows the positive control). The specificity was $100 \%$ (95\% CI $78.20 \%$ $100.00 \%), 100 \%(92.13 \%-100.00 \%)$ of LytA and SP 2038 genes respectively for all DNA of 
non-pneumococcal strains representing several genera of gram-positive and gram-negative bacteria, some of which inhabit the oral cavity.

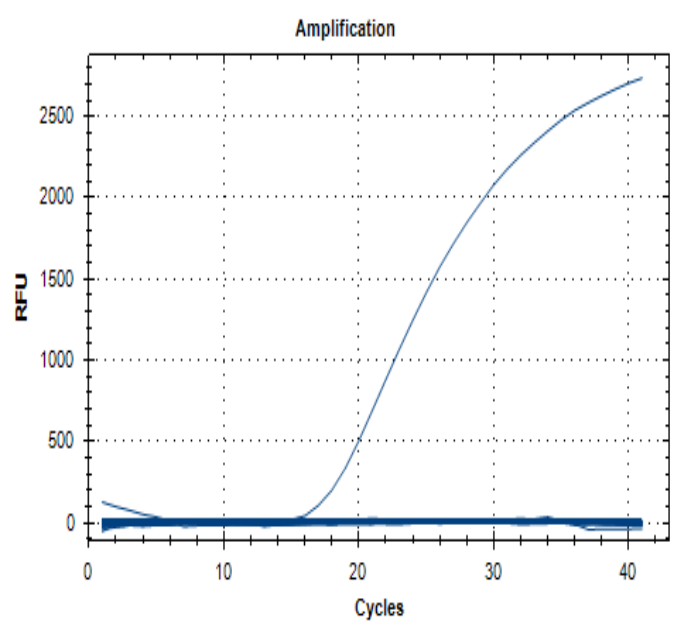

Fig. 2. Specificity test amplification profile generated by the CFX 96 (The exponential curve shows the positive control).

The standardization of molecular biology methods has become an obligation to guarantee the performance and quality of results provided by laboratories [6].

The pre-PCR-TR DNA extraction step is considered a critical step in molecular biology and must meet a number of qualitative and quantitative criteria.

The contamination phenomena can be observed when using analytical DNA extraction systems and may affect samples (inter-sample contamination).

In this study we checked the inter-sample contamination rate which is recorded a percentage of $-0.03 \%$, which is in agreement with an absence of inter-sample contamination. The same result stated in a study performed in France [6]

The spectrophotometric technique is the main method for assessing the quantity and quality of nucleic acids and is considered a quantitative method according to Cofrac criteria [8]. The spectrophotometric assay method is based on the measurement of DNA extract at $260 \mathrm{~nm}$ from a small sample volume (1-2 ul) [7]. The measured repeatability and intermediate fidelity have a covariance $\mathrm{CV}<7$ a same percentage was published in one study
[6].Calculated percentage of CVs differ according to the level of concentration. This difference is due to the variations of the initial quantity in the CSF.

The validation of DNA extraction method was based on an inter-laboratory study of the criteria of repeatability and inter-sample contamination. This method presents good validation criteria that satisfy the laboratory need.

In recent years, good scientific practice has become a requirement for diagnosis and scientific publication, a number of regulatory bodies require tests to be validated to certain standards, such as the FDA (United States food and drug administration) and CLIA (United States clinical laboratory improvement amendments) requirements in the US and the IVD (In-vitro diagnostic products.) Regulations (EU) 2017/7462017 in Europe. [12].

All parameters evaluated in the real-time PCR phase met the recommended requirement for molecular biology. The sensitivity and specificity of the two genes (SP 2038(Commercial kits) and Lyt A (Laboratory developed test)) of the diagnosis recorded a percentage of $100 \%$. The same results have been cited in several studies for the Lyt A gene regardless of whether for singlplex or multiplex tests [13-14].

Commercial kits are more expensive than Laboratory developed test, although commercial assays are typically FDA approved this does not necessarily mean the assay has been validated [12].

Early detection and rapid differentiation of the pathogen play an extremely important role in reducing mortality and morbidity from bacterial meningitis. Conventional diagnostic methods have a very low confirmation rate compared to molecular diagnosis. Several studies have demonstrated a poor ability to detect the pathogen responsible for meningitis compared to culture; in one study only $16 / 220$ CSF were detected by culture and 11 in 277 CSF samples were confirmed in another study [16-17].

Real-time PCR is a rapid, sensitive, and specific technique that has become necessary in the management of meningitis and in routine diagnosis, especially for culture-negative and unknown samples [18]. 
Due to the great advantages and performance of molecular diagnosis by realtime PCR, several countries introduced this technique as a routine method for rapid sensitive and specific diagnosis especially for culture-negative or difficult to culture specimens. [15]

Though with its advantages of real-time PCR the World Health Organization did not consider this technique as a reference method due to the high cost of molecular tests [16].

\section{Conclusion}

The parameters evaluated met the performance criteria of pre-PCR and real-time PCR steps, they recorded a very high sensitivity and specificity for the two diagnostic genes LytA and SP2038.The performance of this technique makes it necessary in the management of meningitis cases especially for culture negative CSF.

\section{Reference}

[1] WHO, Weekly epidemiological record 6 APRIL, 87th YEAR

No, 129-144 (2012).

[2] M. Bouskraoui, Les méningites bactériennes au service de pédiatrie du CHU Mohammed VI (2018).

[3] M. A. Yahia and O. Balach, Int $J$ Pharm Pharm Sci, vol. 6, no. 6, pp. 425-426, (2014).

[4] J. Mcavin, P.A. Reilly, R.M. Roudabush, W. J. BARNES, A Salmen,G. W. Jackson, K.K. Beninga, A Astorga, F.K. Mccleskey,W. Huff,D. Niemeyer, AND K,L. Lohman, J. Clin. Microbiol., vol. 39, no. 10, pp. 3446-3451, (2001).

[5] G. Croville, Séquençage et PCR à haut débit : application à la détection et la caractérisation d'agents pathogènes respiratoires aviaires et au contrôle de pureté microbiologique des vaccins Guillaume, HAL Id : tel-02106661 de l 'Université de reche rch," (2019).

[6] A. Harlé, M. Lion, M. Husson, C. Dubois, and J. L. Merlin, Biol. Clin. (Paris)., vol. 71, no. 5, pp. 608-614, (2013).

[7] S. J. Ahn, J. Costa, and J. R. Emanuel," Nucleic Acids Res., vol. 24, no. 13, pp. 26232625, (1996).

[8] SH GTA 14 - Révision \#01. Cofrac," 2011.

[9] A. Bidossi et al., PLoS One, vol. 7, no. 3 , (2012).

\footnotetext{
*Corresponding author: soumayachaiboub@gmail.com
}

[10] WHO/IVB.11.09, , 2nd ed., no. 2, (2011), p. 56.

[11] M. Cheesebrough, in District Laboratory Practice in Tropical Countries, 2nd editio. Cambridge University Press, Cambridge, UK, (2007).

[12] Melvyn Smith, Viapath Analytics, Specialist Virology Centre, King's College NHS Foundation Trust, London, United Kingdom, Encyclopedia of Virology, 4th Edition, Volume 5 doi:10.1016/B978-0-12814515-9.00053-9,(2021).

[13] N. D. Olson and J. B. Morrow, BMC Res. Notes, vol. 5, no. 1, pp. 2-14, (2012).

[14] E. Van Gastel, P. Bruynseels, and W. Verstrepen, Eur J Clin Microbiol Infect Dis, vol. 26, pp. 651-653, (2007).

[15] I. Diawara, K. Katfy, K. Zerouali, H. Belabbes, and N. Elmdaghri," J Infect Dev Ctries, vol. 10, pp. 053-061, (2016).

[16] K. Wagner, B. Springer, V. P. Pires, and M. Keller, J. Clin. Microbiol., vol. 56, no. 2, pp. 01492-1, 2018.

[17] C. T. Sacchi et al" PLoS One, vol. 6, no. $6,(2011)$.

[18] A. Bidossi et al "PLoS One, vol. 7, no. $3,(2012)$.

[19] OMS,Normes de surveillance des maladies évitables par la vaccination,(2018) 